\title{
The Impact of Internal Audit Outsourcing on the Independence of Internal Audit
}

\author{
Zhao Dongping \\ Jilin Communications Polytechnic Jilin, Changchun, 130012
}

Keywords: Internal audit outsourcing, Internal audit, Independence, Impact

\begin{abstract}
Internal audit is an important way for enterprise internal supervision, which plays a binding role in certain activities of the enterprise that include operation, decision-making and others. However, as the relevant personnel of internal audit are supplied by enterprise itself, the actual independence of internal audit will be affected in different degrees, which may impact the enterprise supervision. With people's increasing requirements for auditing transparency, internal audit outsourcing has become a direction of development. Many enterprises adopt such method to protect the independence of internal audit, and thus effectively enhance the enterprises supervision. This paper, discusses the impact of internal audit outsourcing on the independence of internal audit.
\end{abstract}

\section{Introduction}

China's enterprise management audit system mainly includes three aspects: social, state and internal audit, of which internal audit plays an important role in restraining and supervising enterprises. Internal audit in our country started a little bit late, and many large enterprises set up internal audit to meet the system and its own needs, and also to relieve the social pressure on corporate audit transparency. However, for small and medium enterprises, because of the cost involved in setting up the internal audit, SMEs usually only have one or two staffs take the work to control the cost of enterprise management in a general way, which fails to achieve the independence of the audit work.

After China's auditing system is refined, internal audit has played a certain role in the decision-making and operation of Chinese enterprises. However, due to the late start, the relevant settings of internal auditing are not in place and have great limitations. With the development of society, a large part of the enterprises have begun to implement the internal audit outsourcing. In this way, on the basis of improving the independence of internal audit, the enterprises also effectively control the management costs and solve the defects of internal audit.

\section{Introduction to Internal Audit Outsourcing}

Connotation of Internal Audit Outsourcing: Internal audit is an objective and independent advisory and validation activity designed to enhance value and improve the organization operations. Internal audit is the process of evaluating and improving risk management, control and governance processes by using normative and systematic methods to facilitate the achievement of organization goals.

The internal audit outsourcing means that the external auditors of the enterprise carry out the internal audit work, which mainly includes the following two aspects. Firstly, the audit tasks of the enterprise shall be conducted by the internal auditors and the external auditors of the enterprise. Secondly, the entire audit work of the enterprise shall be conducted by the external auditors. The internal audit outsourcing has gradually become the trend of social development, which reflects the direction of social division specialization. The internal audit outsourcing plays a rather important role for the development of enterprises. It lays a solid foundation for it and effectively promotes the completion of business goals to some extent.

It can be divided into the following three types of forms:

a) Audit management consulting: the internal auditors of the enterprise are required to provide the relevant consultation service for the internal auditors of the enterprise for the better progress of 
the audit work.

b) Outsourcing: the external auditors of the enterprise are required to provide audit service for the enterprise without audit institutions which need to disclose the relevant information of the enterprise.

c) Partial outsourcing: part of the highly difficult audit work cannot be solved due to the lack of the comprehensive quality of the internal auditors. part of the highly difficult audit work is required to be outsourced due to the And it is necessary to outsource this type of highly difficult audit work and receive audit services provided by the external audit professionals for the enterprise.

\section{The Impact of Internal Audit Outsourcing on the Independence of Internal Audit}

The advantages of the internal audit outsourcing are very obvious for the internal audit of enterprises, which specifically includes the following four parts. It may guarantee the quality of the internal audit, conduct an objective assessment of the operation, enhance the internal audit independence and control the operating costs of the enterprise. Internal Audit Outsourcing has an impact on the independence of internal audit.

The most basic function of enterprise internal audit is to examine and judge internal system of an organization by auditing, which aims at management and internal control of the enterprise, followed by objective estimation of efficiency and control's adequacy. Finally audit report based on audit findings would be submitted to executives. The internal audit work needs to guarantee a certain degree of independence to ensure the functions of the internal audit authority. However, this work cannot be completely independent in the management of an enterprise despite the common practice that a special institution is established to conduct internal auditing. The independence and objectivity of internal audit fail to meet the relevant standard due to such reasons as corporate culture. There is no way to achieve fairness and objectivity in related evaluation, judgment and supervision through this kind of internal audit. Nevertheless, the above shortcomings could be avoided and the independence and objectivity of internal audit would be effectively enhanced with the externalization of internal audit. In the internal audit outsourcing, the related staffs are beyond the enterprise and have a higher level of expertise. The internal audit would be relatively more objective, for the staffs are independent from inner-enterprise, both its managers and owners, and wouldn't have unnecessary interest conflicts with relevant departments. By internal audit outsourcing, the independence and objectivity of the actual audit work are still better than those of the full internal audit though internal staffs of enterprises are involved in the audit work.

As a very important condition to guarantee the quality of audit work, the more independent the audit is, the more valuable the result is. Audit environment is a very important factor in the process of audit work, at this stage, the internal audit work of many companies is not independent enough, it needs to be supported by the relevant departments. Since many internal auditors are employees of the company, they often do not conduct internal audits objectively as they are subject to livelihood and work pressure because they are all paid by the company. In particular, the behavior of the leaders cannot be evaluated objectively and the problems are usually ignored. There are also many other situations, due to the existence of informal organizations within the company, the objectivity and independence of the internal audit is greatly affected. Therefore, the internal audit work needs independence, and only way to avoid the above issues is to maintain the independence of internal audit. The audit staff should be independent from the audit environment and be out of line with the other employees of the enterprise so that during the internal audit process, if certain materials are needed, they can be directly requested from the relevant personnel. This can generally guarantee the objectivity as well as the independence without worrying about the destruction of the relationship with the other employees. On the other hand, because of the externalization of internal audit, the auditors do not have to worry about pay issues. Through such forms of internal audit, the independence of internal audit can be effectively protected, the result of the actual audit work is relatively reliable and fair, and has greater reference value.

Enterprise internal audit sites are generally within the enterprise, business employees will participate in the internal audit of the entire process, so the objectivity of the internal audit of the 
enterprise and the authority has been a certain extent, it is difficult to take timely detection and solution of the essence of the enterprise issues. Specifically including the internal control of enterprises, as the internal audit of enterprises is very difficult to check out.

Especially for small and medium-sized enterprises, it is very difficult for the internal audit institutions and financial institutions to realize their independence, so there will be problems of corporate fraud. Under such circumstances, the internal audit of enterprises becomes more obvious if they are not independent. Externalizing enterprise internal audit can realize the independence of the audit work, not with the company's entire operating system, through the external audit professionals to judge and review the company, effectively protect the independence of internal audit, play an important role in enhancing the audit work supervisory functions.

\section{Conclusions}

Externalizing the place on put together is narrated, internal audit has gradually become the trend of the development of the audit, the form can help enterprises to obtain more high quality service, to further promote the realization of the goal of enterprise. However, the internal audit of externalization also has some disadvantages, you need to get the attention of enterprises, in accordance with the actual business management and management model, in the process of practice, choose the most suitable internal audit of the external form of enterprise, as far as possible play to the advantages of internal audit externalized, to avoid disadvantages, lay a solid foundation for the development of enterprises.

\section{References}

[1] Liu Rui. Comprehensive Study of Externalization of Internal Audit [J]. Assets and Finances in Administration and Institution, 2017(20):77-78.

[2] Guo Luxue, Liu Bo. Research on SME Internal Audit Externalization Based on SWOT Analysis [J]. Business accounting, 2017(6):55-56.

[3] Zhong Junhua, Xing Fumei. Research on External Audit of Enterprise Internal Audit in China [J]. CO-Operative Economy \& Science, 2016(1):136-138.

[4] Zhang Aihua. Analysis of External Audit of Small and Medium Enterprises [J]. Research on Modern State - owned Enterprises, 2016(8).

[5] Li Yansong. Discussion about the External Audit and Positioning in Colleges and Universities under the New Normalcy [J]. Modern Economic Information, 2016(36). 